\title{
Correlates of unprotected sex by client type among female sex workers that inject drugs in Tijuana and Ciudad Juarez, Mexico
}

\author{
Ryan P. Lindsay ${ }^{1}$, Scott C. Roesch ${ }^{2}$, Steffanie A. Strathdee ${ }^{3}$, M. Gudelia Rangel ${ }^{4}$, Hugo S. Staines-Orozco ${ }^{5}$, \\ Daniela Abramovitz ${ }^{3}$, Monica D. Ulibarri ${ }^{6}$, and Melanie L.A. Rusch ${ }^{7}$ \\ ${ }^{1}$ Department of Community and Public Health, Idaho State University-Meridian Campus, Meridian, ID, United States \\ ${ }^{2}$ Department of Psychology, San Diego State University, San Diego, CA, United States \\ ${ }^{3}$ Department of Medicine, University of California San Diego, La Jolla, CA, United States \\ ${ }^{4}$ Secretaría de Salud y Comisión de Salud Fronteriza México-Estados Unidos, Tijuana, BC, Mexico \\ ${ }^{5}$ Instituto de Ciencias Biomédicas, Universidad Autónoma de Ciudad Juarez, Juárez, Chih., Mexico \\ ${ }^{6}$ Department of Psychiatry, University of California San Diego, La Jolla, CA, United States \\ ${ }^{7}$ Vancouver Island Health Authority, Victoria, British Columbia, Canada
}

\begin{abstract}
Aims: Risk environment factors may influence unprotected sex between female sex workers who are also injection drug users (FSW-IDUs) and their regular and non-regular clients differently. Our objective is to identify correlates of unprotected vaginal sex in the context of client type.

Methods: A cross-sectional survey of 583 FSW-IDUs in Tijuana and Ciudad Juarez, Mexico, was analyzed using negative binomial regression to determine physical, social, economic, and policy risk-environment factors that affect the frequency of unprotected sex with regular and non-regular clients.

Results: Median number of unprotected vaginal sex acts in the past month among FSW-IDUs and their regular and non-regular clients was 11 (IQR 3-30) and 13 (IQR 5-30), respectively. Correlates differed by site and client type and were most closely associated with the risk environment. In Tijuana, social factors (e.g., injecting drugs with clients) were independently associated with more unprotected sex. Factors independently associated with less unprotected sex across client type and site included social and economic risk environment factors (e.g., receiving more money for unprotected sex). In the policy risk environment, always having free access to condoms was independently associated with less unprotected sex among non-regular clients in Tijuana (Risk rate ratio $=0.64 ; 95 \%$ confidence interval 0.43-0.97).
\end{abstract}

Conclusions: Primarily physical, social, and economic risk-environment factors were associated with unprotected vaginal sex between FSW-IDUs and both client types, suggesting potential avenues for intervention.

Unprotected sex between female sex workers who are also injection drug users (FSW-IDUs) and their clients represents an intersection of multiple high-risk behaviors for transmission of HIV and other sexually transmitted infections (STIs) (Alary \& Lowndes, 2004). Rates of condom use are lower among IDU populations compared to those who do not inject, and injection drug use is associated with unprotected sex among HIV-positive women (Buchacz et al., 2001; Campsmith, Nakashima, \& Jones, 2000; Wilson et al., 1999), and among FSWs (Lau et al., 2007). Research in Tijuana and Ciudad Juarez (Cd. Juarez), Mexico, showed that a similar proportion of FSWs and FSW-IDUs (38\% vs. 43\%, respectively) reported often or always having unprotected vaginal sex with clients, but FSW-IDUs had a significantly higher number of unprotected vaginal acts (Strathdee et al., 2008).
Additionally, FSW-IDUs earned less money for sex with and without a condom compared to FSWs (Strathdee et al., 2008). This highlights the vulnerability FSW-IDUs may experience in accessing and/or negotiating condom use. In Tijuana and Cd. Juarez, correlates of consistent condom use have been described among both FSWs (Munoz et al., 2010) and FSW-IDUs (Gaines et al., 2013), though correlates of unprotected sex have only been explored among the clients of FSWs (Goldenberg et al., 2010) and not among FSW-IDUs.

Among FSW populations, condom use varies by partner type when comparing paid and unpaid relationships (Hong \& Li, 2008; Wang et al., 2007). Differences in the prevalence of condom use by client type have also been reported (Morris, Pramualratana, Podhisita, \& Wawer,

Correspondence: Steffanie A. Strathdee, Department of Medicine, University of California San Diego, 9500 Gilman Dr, La Jolla, CA 92093, United States. Telephone: +18588221952, Fax: +18585347566, Email: sstrathdee@ucsd.edu 
1995; Pettifor et al., 2010; Pickering, Okongo, Nnalusiba, Bwanika, \& Whitworth, 1997; Tran, Le, \& Nguyen, 2008), since many sex workers have both regular (i.e., repeat clients/ongoing relationship) and non-regular paying clients (i.e., clients serviced 1-2 times). Understanding condom use among FSW-IDUs in the context of client type is important, as interventions for promoting condom use may need to be tailored. Typically, unprotected sex is more likely to occur between FSWs and regular clients who return to the same sex worker than FSWs and non-regular clients (Morris et al., 1995; Pettifor et al., 2010; Pickering et al., 1997; Tran et al., 2008). Among clients of FSWs in the United States-Mexico border region, visiting the same FSW was independently associated with unprotected sex (Goldenberg et al., 2010; Semple et al., 2010).

The influence of structural and social factors on HIV transmission among IDUs, sex workers, and their clients is increasingly acknowledged in understanding HIV risk. Rhodes' risk environment framework stipulates that policy, economic, social, and physical risk environments interact and operate at both micro and macro levels of influence on HIV transmission (Rhodes, Singer, Bourgois, Friedman, \& Strathdee, 2005; Rhodes et al., 1999). Applying this framework to the FSW-IDU population in the United States-Mexico border region showed that factors reflecting the risk environment, such as injecting with clients (social) and police confiscation of syringes (policy), were the strongest correlates of HIV infection (Strathdee et al., 2011).

This study applies the risk-environment framework to understand the drivers of unprotected sex among FSWIDUs by client type. Our objective is to identify correlates of unprotected vaginal sex in the context of client type, since regular clients may be solicited or serviced in a different context or location than non-regular clients, and different relationship dynamics by client type may influence condom use.

\section{Methods}

\section{Study sample}

Our sample uses baseline data from Mujer Mas Segura (Safer Women), a behavioral intervention study seeking to reduce the use of shared injection equipment and increase condom use among FSW-IDUs in Northern Mexico (Vera et al., 2012). FSW-IDUs $(n=584)$ were enrolled from Tijuana and Cd. Juarez between October 2008 and July 2010. Outreach workers from local non-governmental organizations already working with FSWs and IDUs recruited participants from street and sex work venues (bars/hotels) during normal outreach activities. For study eligibility, enrollees had to report having unprotected vaginal or anal sex with a male client, injecting drugs, and sharing syringes or injection paraphernalia within the previous month. Enrollees had to speak Spanish or English, provide informed consent, agree to free STI treatment, and have no plans to move to another city in the following 18 months. We further excluded one participant, an outlier with respect to number of unprotected sex acts, leaving 583 for analysis.

Interviewer-administered surveys and HIV/STI testing were conducted at baseline and quarterly follow-up visits; however, the present analysis was restricted to the baseline visit. The institutional review boards at the University of California, San Diego, Tijuana General Hospital, and Universidad Autónoma de Ciudad Juarez approved the study protocol. Detailed information on the intervention and sampling methods (Ramos et al., 2009; Vera et al., 2012) are reported elsewhere.

\section{Measures}

Respondents were asked to report the total number of vaginal sex acts and the number of times a condom was used for vaginal sex with each client type (regular and nonregular) during the previous month (Table 1). Non-regular clients were defined as men who did not come back for regular visits or men who were only serviced once or twice, whereas regular clients were defined as men who returned to the respondent for multiple transactions.

The outcome variable, the number of unprotected vaginal sex acts in the previous month, was calculated by subtracting the number of protected sex acts from the total number of sex acts for each client type. We used the total number of unprotected vaginal sex acts because requiring unprotected sex for study inclusion made a dichotomous measure of consistent condom use unfeasible.

\section{Table 1}

Measures and survey questions

\begin{tabular}{|c|c|}
\hline Measure & Survey questions \\
\hline \multicolumn{2}{|l|}{ Outcome variable } \\
\hline $\begin{array}{l}\text { \# of unprotected vaginal sex acts } \\
\text { with non-regular clients }\end{array}$ & $\begin{array}{l}\text { In the past month, what was the total number of times you used a condom for vaginal sex with non-regular } \\
\text { male clients? }\end{array}$ \\
\hline $\begin{array}{l}\text { \# of unprotected vaginal sex acts } \\
\text { with regular clients }\end{array}$ & $\begin{array}{l}\text { In the past month, what was the total number of times you used a condom for vaginal sex with regular male } \\
\text { clients? }\end{array}$ \\
\hline \multicolumn{2}{|c|}{ Offset variable (for respective client type) } \\
\hline $\begin{array}{l}\text { \# of vaginal sex acts with non- } \\
\text { regular clients }\end{array}$ & In the past month, what was the total number of times you had vaginal sex with non-regular male clients? \\
\hline
\end{tabular}




\begin{tabular}{|c|c|}
\hline Measure & Survey questions \\
\hline $\begin{array}{l}\text { \# of vaginal sex acts with regular } \\
\text { clients }\end{array}$ & In the past month, what was the total number of times you had vaginal sex with regular male clients? \\
\hline \multicolumn{2}{|l|}{ Individual factors } \\
\hline \multicolumn{2}{|l|}{ Sociodemographics } \\
\hline Have spouse/steady partner & Do you have a spouse or steady partner? (Y/N) \\
\hline Have children $<18$ at home & Do you have children under age 18 living with you? (Y/N) \\
\hline Duration in sex work (<10 years) & How old where you when you began to work regularly as a prostitute? \\
\hline \multicolumn{2}{|l|}{ Current individual risk behaviors } \\
\hline $\begin{array}{l}\text { Always use hormonal } \\
\text { contraceptives }\end{array}$ & $\begin{array}{l}\text { In the past } 6 \text { months, how often did you use contraceptives (other than male or female condoms) to prevent } \\
\text { pregnancy? } \\
\text { Response options: Never, Sometimes, Often, Always }\end{array}$ \\
\hline \multicolumn{2}{|l|}{ \# of clients } \\
\hline Non-regular clients & $\begin{array}{l}\text { Now, I would like you to think about your non-regular male clients. By non-regular, we mean men who do } \\
\text { not come back to you for regular visits/men that you have seen only once or twice. In the past month, how } \\
\text { many non-regular male clients did you have? }\end{array}$ \\
\hline Regular clients & $\begin{array}{l}\text { Now, I would like you to think only about your regular male clients. By regular, we mean men who come } \\
\text { back to you for repeat visits/men that you have an ongoing relationship with over time. In the past month, } \\
\text { how many regular male clients did you have? }\end{array}$ \\
\hline \multicolumn{2}{|c|}{ Risk Environment (micro-level) factors } \\
\hline \multicolumn{2}{|l|}{ Physical Risk Environment } \\
\hline Born in current city & In what city or town were you born? \\
\hline Current housing category & In the last month, what kind of place did you live or sleep in most of the time? \\
\hline Stable & Responses: Parent's house, your own house, your spouse's house, you sexual partner's house, apartment \\
\hline Unstable & Responses: Relative's or friend's house, workplace, rented room (hotel or rooming house) \\
\hline Inadequate/homeless & Responses: Car, bus, truck, or other vehicle, abandoned building, on the streets, in a shooting gallery \\
\hline Type of sex worker (street) & Which is the main type of place where you work in prostitution? \\
\hline \multicolumn{2}{|l|}{ Social Risk Environment } \\
\hline $\begin{array}{l}\text { Median \# of people typically } \\
\text { inject with }\end{array}$ & In the past month, when you injected, about how many people did you usually inject with? \\
\hline $\begin{array}{l}\text { Injected with clients around time } \\
\text { of sex }\end{array}$ & $\begin{array}{l}\text { During the past month, how often did you inject drugs with a client around the time you were having sex? } \\
\text { Response options: Never, Sometimes, Often, Always }\end{array}$ \\
\hline $\begin{array}{l}\text { Alcohol use before or during sex } \\
\text { w/ client }\end{array}$ & $\begin{array}{l}\text { During the past month, how often did you use alcohol right before or during sex with a client? } \\
\text { Response options: Never, Sometimes, Often, Always }\end{array}$ \\
\hline $\begin{array}{l}\text { Drug use before or during sex } \\
\text { w/client }\end{array}$ & $\begin{array}{l}\text { During the past month, how often did you use drugs right before or during sex with a client? } \\
\text { Response options: Never, Sometimes, Often, Always }\end{array}$ \\
\hline Condom use self-efficacy scale & $\begin{array}{l}\text { Next, I want you to tell me how much you agree or disagree with each of the following statements. } \\
\text { 1) I can use a condom properly 2) I can use a condom every time I have vaginal or anal sex 3) I can have } \\
\text { condoms available every time I have vaginal or anal sex 4) I can use a condom for sex while under the } \\
\text { influence of drugs or alcohol 5) I can use a condom without any instruction } \\
\text { Response options: Strongly disagree, Disagree, Agree, Strongly agree }\end{array}$ \\
\hline $\begin{array}{l}\text { Positive outcome expectancy for } \\
\text { condom use scale }\end{array}$ & $\begin{array}{l}\text { Here are some more statements about safer sex and condom use. How much do you agree or disagree with } \\
\text { each statement? } \\
\text { I believe that condoms interfere with sexual pleasure 2) I believe that stopping to put on a condom ruins the } \\
\text { moment 3) I believe that condoms will protect me from getting HIV 4) Using a condom will feel unnatural } \\
\text { 5) My client(s) will not be sexually satisfied if we use a condom. } \\
\text { Response options: Strongly disagree, Disagree, Agree, Strongly agree }\end{array}$ \\
\hline \multicolumn{2}{|l|}{ Economic Risk Environment } \\
\hline Income (<3500 pesos/month) & $\begin{array}{l}\text { On average, how much did you earn each month over the past year, before taxes, including legal and illegal } \\
\text { income? }\end{array}$ \\
\hline Can afford to buy own condoms & If you need to buy them, can you afford to buy your own condoms? (Y/N) \\
\hline $\begin{array}{l}\text { Reported earning more for } \\
\text { unprotected sex }\end{array}$ & $\begin{array}{l}\text { Calculated variable: if } a<b \\
\text { a) On average, how much money do you earn in pesos each time you perform vaginal sex using a condom? } \\
\text { b) On average, how much money do you earn in pesos each time you perform vaginal sex without a } \\
\text { condom? }\end{array}$ \\
\hline \multicolumn{2}{|l|}{ Policy Risk Environment } \\
\hline $\begin{array}{l}\text { Always have access to free } \\
\text { condoms }\end{array}$ & $\begin{array}{l}\text { How often can you get condoms for free? } \\
\text { Response options: Never, Sometimes, Often, Always }\end{array}$ \\
\hline Live \& work in same location & $\begin{array}{l}\text { Do you live and work in the same location? For example, some women live in the back of the bar where } \\
\text { they work. }(\mathrm{Y} / \mathrm{N})\end{array}$ \\
\hline
\end{tabular}


Individual sociodemographics and factors known to affect condom use (i.e., having a spouse/steady partner, hormonal contraceptive use, duration in sex work, drug use) were included as covariates. Covariates representing the physical risk environment included housing stability, primary location where sex is solicited (street versus other) and being native to the interview city. The social risk environment included number of people the respondent typically injects with, drug or alcohol use before or during sex with a client, frequency of injection drug use around the time of sex, condom use self-efficacy (five-item scale developed by Jamner, Wolitski, Corby, and Fishbein (1998) to measure ability to properly use condoms and negotiate condom use) and condom outcome expectancies (six-item measure of expectations for condom use, developed for use with FSWs in Mexico (Patterson et al., 2008)). Both the self-efficacy and outcome expectancy scales used a fourpoint Likert scale for response options ( 1 = strongly agree to $4=$ strongly disagree) and were modeled as continuous variables. The economic risk environment included income, ability to afford condoms, and whether or not the respondents reported exchanging unprotected sex in return for more money. The policy risk environment included access to free condoms and whether sex work was conducted in the same location where one lives.

\section{Statistical Analysis}

Bivariate and multivariate associations between individual and risk environment covariates and the number of unprotected vaginal sex acts were assessed using negative binomial regression with risk rate ratios that accounted for over-dispersion. The logarithm of the total number of vaginal sex acts per respective client type was our offset variable and robust variance estimation was used.

Significant bivariate associations were included in manual forward stepwise selection of covariates (entry alpha $<0.1$; exit alpha > 0.05). A hierarchical "block" analysis was used to first analyze individual correlates, which if significant were "locked" into the model, followed by all risk-environment variables (Victora, Huttly, Fuchs, \& Olinto, 1997). This method allowed examination of the impact of theorized risk environment covariates after controlling for individual factors. Models were stratified by client type (i.e., regular vs. non-regular clients). Though not an a priori hypothesis, study sites were known to have significant differences in individual and risk-environment variables from previous analysis (Strathdee et al., 2013), thus stratification by study site was necessary (Table 2). Lack of collinearity between covariates was determined using tolerance values (cutoff $>0.1$ ). Analyses were performed using Stata version 11 (Stata Corp).

Table 2

Individual-level and risk environment characteristics of FSW-IDUs in Ciudad Juarez and Tijuana, Mexico

\begin{tabular}{|c|c|c|c|}
\hline Variable & $\begin{array}{c}\text { Ciudad Juarez } \\
(n=300) \\
\%(95 \% \text { CI })\end{array}$ & $\begin{array}{c}\text { Tijuana } \\
(n=283) \\
\%(95 \% \mathrm{CI})\end{array}$ & $p$ value \\
\hline \multicolumn{4}{|l|}{ Individual factors } \\
\hline \multicolumn{4}{|l|}{ Sociodemographics } \\
\hline Age $(<25)$ & $18.7(14.2-23.1)$ & $12.0(8.2-15.8)$ & 0.026 \\
\hline Have spouse/steady partner & $39.0(33.5-44.5)$ & $37.8(32.1-43.5)$ & 0.768 \\
\hline Have children $<18$ at home & $43.7(37.9-49.6)$ & $32.0(26.2-37.8)$ & 0.005 \\
\hline Duration in sex work (< 10 years) & $45.7(40.0-51.3)$ & $43.6(37.8-49.4)$ & 0.744 \\
\hline \multicolumn{4}{|l|}{ Current individual risk behaviors } \\
\hline Always use hormonal contraceptives & $34.8(29.3-40.2)$ & $23.7(18.7-28.6)$ & 0.003 \\
\hline Inject drugs more than once a day & $85.3(81.3-89.4)$ & $94.7(92.1-97.3)$ & $<0.001$ \\
\hline \multicolumn{4}{|l|}{ Median \# of clients (IQR) } \\
\hline Non-regular clients & $51(20-95)$ & $8(3-16)$ & $<0.001$ \\
\hline Regular clients & $4(2-6)$ & $7(3-15)$ & $<0.001$ \\
\hline \multicolumn{4}{|l|}{ Risk Environment (micro-level) factors } \\
\hline \multicolumn{4}{|c|}{ Physical Risk Environment } \\
\hline Born in current city & $70.2(65.0-75.5)$ & $50.6(44.4-56.8)$ & $<0.001$ \\
\hline Current housing category & & & $<0.001$ \\
\hline Stable & $50.3(44.7-56.0)$ & $25.5(20.4-30.6)$ & \\
\hline Unstable & $46.7(41.0-52.3)$ & $61.0(54.9-66.4)$ & \\
\hline Inadequate/homeless & $3.0(1.1-4.9)$ & $13.8(9.7-17.9)$ & \\
\hline Type of sex worker (street) & $61.5(56.0-67.1)$ & $74.5(69.4-79.6)$ & 0.001 \\
\hline
\end{tabular}




\begin{tabular}{|c|c|c|c|}
\hline Variable & $\begin{array}{c}\text { Ciudad Juarez } \\
(n=300) \\
\%(95 \% \text { CI })\end{array}$ & $\begin{array}{c}\text { Tijuana } \\
(n=283) \\
\%(95 \% \text { CI })\end{array}$ & $p$ value \\
\hline \multicolumn{4}{|l|}{ Social Risk Environment } \\
\hline \multicolumn{4}{|l|}{ Median \# of vaginal sex acts (IQR) } \\
\hline Non-regular clients & $60(25-98)$ & $10(5-20)$ & $<0.001$ \\
\hline Regular clients & $16(8-30)$ & $20(5-40)$ & 0.806 \\
\hline \multicolumn{4}{|l|}{ Median \# of unprotected vaginal sex acts } \\
\hline Non-regular clients & $20(7-50)$ & $10(3-17)$ & $<0.001$ \\
\hline Regular clients & $8(3-16)$ & $18(4-38)$ & $<0.001$ \\
\hline Median \# of people typically inject with (IQR) & $3(2-5)$ & $3(1-5)$ & 0.751 \\
\hline Injected with clients around time of sex & $74.5(69.4-79.6)$ & $57.3(51.7-63.0)$ & $<0.001$ \\
\hline Condom use self-efficacy (mean, CI, range $=1-4$ ) & $2.88(2.81-2.94)$ & $2.82(2.76-2.88)$ & 0.200 \\
\hline Positive outcome expectancy for condom use (mean, CI, range=1-4) & $2.74(2.67-2.80)$ & $2.61(2.56-2.66)$ & 0.003 \\
\hline \multicolumn{4}{|l|}{ Economic Risk Environment } \\
\hline Income (< 3500 pesos/month) & $39.7(34.1-45.2)$ & $64.7(59.1-70.3)$ & $<0.001$ \\
\hline Can afford to buy own condoms & $64.4(59.0-69.9)$ & $46.8(40.9-52.7)$ & $<0.001$ \\
\hline Reported earning more for unprotected sex & $62.7(57.2-68.3)$ & $28.7(23.2-34.1)$ & $<0.001$ \\
\hline \multicolumn{4}{|l|}{ Policy Risk Environment } \\
\hline Always have access to free condoms & $1.7(0.2-3.1)$ & $8.5(5.2-11.8)$ & $<0.001$ \\
\hline Live \& work in same location & $23.3(18.5-28.1)$ & $21.2(16.4-26.0)$ & 0.240 \\
\hline
\end{tabular}

\section{Results}

Of 583 FSW-IDUs, $87.5 \%$ had non-regular clients and 85.8\% had regular clients in the past month. The aggregated proportion of unprotected vaginal sex was $83.9 \%$ in Tijuana and $58.2 \%$ in Cd. Juarez for regular clients and $74.5 \%$ and $50.3 \%$ respectively for non-regular clients. Mean number of unprotected vaginal sex acts varied significantly by study site and client type (see Table 2). Respondents in Cd. Juarez had more non-regular clients than those in Tijuana (median: 51 vs. 8; $p<0.001$, respectively), with whom they reported more vaginal sex acts in the prior month (median: 60 vs. 10; $p<0.001$ ). Differences in the physical, economic, social, and policy risk environments between Tijuana and Cd. Juarez are also presented in Table 2.

\section{Bivariate Results}

\section{Non-regular clients}

In Tijuana, factors associated with fewer unprotected sex acts with non-regular clients included having a spouse/steady partner, being able to afford condoms (economic), and always having free access to condoms (policy), while having more regular clients and using hormonal contraceptives in the previous six months, streetbased sex work (physical), drug or alcohol use before or during sex with client (social), injecting drugs with clients around time of sex (social), and earning $<3500$ pesos per month (economic) were associated with a greater frequency of unprotected sex acts with non-regular clients (Table 3). In Cd. Juarez, unprotected sex acts with non-regular clients were associated with inadequate housing/homelessness (physical).

In both cities, injecting with more people (social) was associated with more unprotected sex acts with non-regular clients while higher self-efficacy regarding condom use (social), positive outcome expectancy for condom use (social), and earning more for unprotected sex (economic) were associated with fewer unprotected sex acts with nonregular clients.

\section{Regular clients}

In Tijuana, duration in sex work for $<10$ years, always using hormonal contraceptives in the previous six months, injection drug use around the time of sex (social) and earning < 3500 pesos per month (economic) were associated with a higher frequency of unprotected sex with regular clients. Having a spouse/steady partner or having children $<18$ years old at home were associated with fewer unprotected sex acts with regular clients.

In Cd. Juarez, having more non-regular clients, younger age, unstable or inadequate housing/homelessness (physical), and alcohol use before sex with clients (social) were associated with more unprotected sex acts with regular clients.

In both cities, higher positive outcome expectancy for condom use (social), self-efficacy regarding condom use (social), ability to afford condoms (economic), and earning more for unprotected sex (economic) were negatively associated with the number of unprotected sex acts with regular clients. 
Table 3

Results of bivariate negative binomial regression of unprotected vaginal sex acts by client type among FSW-IDUs in Ciudad Juarez

\begin{tabular}{|c|c|c|c|c|}
\hline \multirow[b]{2}{*}{ Variable } & \multicolumn{2}{|c|}{$\begin{array}{l}\text { \# of unprotected sex acts } \\
\text { with non-regular clients } \\
\text { (n=283) }\end{array}$} & \multicolumn{2}{|c|}{$\begin{array}{l}\text { \# of unprotected sex acts } \\
\text { with regular clients } \\
(n=253)\end{array}$} \\
\hline & RRR & $95 \%$ CI & RRR & $95 \%$ CI \\
\hline \multicolumn{5}{|l|}{ Individual factors } \\
\hline \multicolumn{5}{|l|}{ Sociodemographics } \\
\hline Age $(<25)$ & 0.89 & $0.73-1.08$ & 0.78 & $0.63-0.97$ \\
\hline Have spouse/steady partner & 0.90 & $0.78-1.04$ & 0.92 & $0.78-1.10$ \\
\hline Have children $<18$ at home & 0.99 & $0.86-1.15$ & 0.99 & $0.84-1.17$ \\
\hline Duration in sex work (< 10 years) & 0.96 & $0.84-1.11$ & 0.97 & $0.82-1.13$ \\
\hline \multicolumn{5}{|l|}{ Current individual risk behaviors } \\
\hline Hormonal contraceptive use (always vs. less than always) & 1.09 & $0.95-1.25$ & 1.04 & $0.88-1.22$ \\
\hline Injection frequency (more than 1 time daily vs. once daily or less) & 1.14 & $0.92-1.41$ & 1.22 & $0.95-1.57$ \\
\hline \multicolumn{5}{|l|}{ \# of clients (by client type) } \\
\hline Non regular & - & - & 1.001 & $1.000-1.003$ \\
\hline Regular & 1.001 & $0.993-1.001$ & - & - \\
\hline \multicolumn{5}{|l|}{ Risk Environment (micro-level) factors } \\
\hline \multicolumn{5}{|l|}{ Physical Risk Environment } \\
\hline Born in current city & 0.98 & $0.84-1.15$ & 0.97 & $0.82-1.16$ \\
\hline \multicolumn{5}{|l|}{ Housing categories (ref $=$ stable) } \\
\hline Unstable & 1.05 & $0.91-1.22$ & 1.02 & $0.87-1.20$ \\
\hline Inadequate/homeless & 1.61 & 1.37-1.89 & 1.51 & 1.12-2.02 \\
\hline Type of sex worker (street vs. other) & 1.06 & $0.91-1.22$ & 1.11 & $0.93-1.32$ \\
\hline \multicolumn{5}{|l|}{ Social Risk Environment } \\
\hline Number of people typically inject with & 1.02 & 1.00-1.03 & 1.00 & $0.99-1.02$ \\
\hline Alcohol use before or during sex w/ client (any vs. never) & 1.04 & $0.90-1.21$ & 1.20 & $1.01-1.43$ \\
\hline Drug use before or during sex w/ client (any vs. never) & 1.01 & $0.76-1.33$ & 0.97 & $0.70-1.32$ \\
\hline Injected with clients around time of sex & 1.07 & $0.88-1.29$ & 1.19 & $0.98-1.44$ \\
\hline Condom use self-efficacy (mean, CI, range = 1-4) & 0.85 & $0.79-0.92$ & 0.85 & $0.79-0.92$ \\
\hline Positive outcome expectancy for condom use (mean, CI, range $=1-4$ ) & 0.89 & $0.83-0.94$ & 0.89 & $0.82-0.95$ \\
\hline \multicolumn{5}{|l|}{ Economic Risk Environment } \\
\hline Income (<3500 pesos/month) & 1.08 & $0.93-1.25$ & 1.15 & $0.98-1.35$ \\
\hline Afford to buy your own condoms (Yes vs. No) & 0.87 & $0.75-1.01$ & 0.80 & $0.69-0.94$ \\
\hline Reported earning more for unprotected sex & 0.79 & $0.69-0.90$ & 0.77 & $0.66-0.90$ \\
\hline \multicolumn{5}{|l|}{ Policy Risk Environment } \\
\hline Free access to condoms (always vs. less than always) & 0.63 & $0.29-1.38$ & 0.70 & $0.35-1.38$ \\
\hline Live \& work in same location & 1.09 & $0.93-1.28$ & 0.99 & $0.83-1.19$ \\
\hline
\end{tabular}

Negative binomial models were offset by the number of vaginal sex acts with respective client type with robust variance estimation

Results of bivariate negative binomial regression of unprotected vaginal sex acts by client type among FSW-IDUs in Tijuana, Mexico

\begin{tabular}{|c|c|c|c|c|}
\hline \multirow[b]{2}{*}{ Variable } & \multicolumn{2}{|c|}{$\begin{array}{l}\text { \# of unprotected sex acts } \\
\text { with non-regular clients } \\
\qquad(n=227)\end{array}$} & \multicolumn{2}{|c|}{$\begin{array}{l}\text { \# of unprotected sex acts } \\
\text { with regular clients } \\
(n=247)\end{array}$} \\
\hline & $\mathbf{R R R}$ & $95 \% \mathrm{CI}$ & RRR & $95 \%$ CI \\
\hline \multicolumn{5}{|l|}{ Individual factors } \\
\hline \multicolumn{5}{|l|}{ Sociodemographics } \\
\hline Age $(<25)$ & 1.08 & $0.94-1.24$ & 1.03 & $0.92-1.15$ \\
\hline Have spouse/steady partner & 0.83 & $0.72-0.95$ & 0.89 & $0.80-0.98$ \\
\hline Have children $<18$ at home & 0.93 & $0.80-1.07$ & 0.89 & $0.81-0.99$ \\
\hline Duration in sex work (< 10 years) & 1.03 & $0.92-1.16$ & 1.09 & 1.01-1.18 \\
\hline \multicolumn{5}{|l|}{ Current individual risk behaviors } \\
\hline Hormonal contraceptive use (always vs. less than always) & 1.21 & $1.08-1.36$ & 1.14 & $1.05-1.24$ \\
\hline Injection frequency (more than 1 time daily vs. once daily or less) & 1.19 & $0.82-1.74$ & 0.99 & $0.85-1.14$ \\
\hline
\end{tabular}




\begin{tabular}{|c|c|c|c|c|}
\hline \multirow[b]{2}{*}{ Variable } & \multicolumn{2}{|c|}{$\begin{array}{l}\text { \# of unprotected sex acts } \\
\text { with non-regular clients } \\
\qquad(n=227)\end{array}$} & \multicolumn{2}{|c|}{$\begin{array}{l}\text { \# of unprotected sex acts } \\
\text { with regular clients } \\
(n=247)\end{array}$} \\
\hline & RRR & $95 \%$ CI & RRR & $95 \%$ CI \\
\hline \multicolumn{5}{|l|}{ \# of clients (by client type) } \\
\hline Non regular & - & - & 1.0004 & $0.999-1.002$ \\
\hline Regular & 1.006 & $0.999-1.012$ & - & - \\
\hline \multicolumn{5}{|l|}{ Risk Environment (micro-level) factors } \\
\hline \multicolumn{5}{|l|}{ Physical Risk Environment } \\
\hline Born in current city & 1.04 & $0.93-1.17$ & 0.97 & $0.90-1.05$ \\
\hline \multicolumn{5}{|l|}{ Housing categories (ref $=$ stable) } \\
\hline Unstable & 0.97 & $0.85-1.12$ & 0.92 & $0.86-0.99$ \\
\hline Inadequate/homeless & 0.99 & $0.82-1.20$ & 0.85 & $0.72-1.00$ \\
\hline Type of sex worker (street vs. other) & 1.92 & $1.28-2.87$ & 1.02 & $0.92-1.13$ \\
\hline \multicolumn{5}{|l|}{ Social Risk Environment } \\
\hline Number of people typically inject with & 1.00 & $1.00-1.01$ & 1.00 & $1.00-1.00$ \\
\hline Alcohol use before or during sex w/ client (any vs. never) & 1.11 & $1.00-1.24$ & 1.02 & $0.94-1.10$ \\
\hline Drug use before or during sex w/ client (any vs. never) & 1.44 & $1.03-2.02$ & 1.09 & $0.93-1.27$ \\
\hline Injected with clients around time of sex & 1.30 & $1.13-1.50$ & 1.30 & 1.17-1.45 \\
\hline Condom use self-efficacy (mean, CI, range $=1-4$ ) & 0.81 & $0.74-0.88$ & 0.91 & $0.84-0.98$ \\
\hline $\begin{array}{l}\text { Positive outcome expectancy for condom use (mean, CI, range = 1- } \\
\text { 4) }\end{array}$ & 0.86 & $0.79-0.94$ & 0.88 & $0.81-0.96$ \\
\hline \multicolumn{5}{|l|}{ Economic Risk Environment } \\
\hline Income ( $<3500$ pesos/month) & 1.25 & 1.06-1.47 & 1.15 & $1.03-1.30$ \\
\hline Afford to buy your own condoms (Yes vs. No) & 0.77 & $0.67-0.88$ & 0.88 & $0.80-0.97$ \\
\hline Reported earning more for unprotected sex & 0.73 & $0.60-0.88$ & 0.74 & $0.64-0.85$ \\
\hline \multicolumn{5}{|l|}{ Policy Risk Environment } \\
\hline Free access to condoms (always vs. less than always) & 0.46 & $0.28-0.77$ & 0.56 & $0.36-0.85$ \\
\hline Live \& work in same location & 0.88 & $0.75-1.02$ & 0.97 & $0.87-1.08$ \\
\hline
\end{tabular}

Negative binomial models were offset by the number of vaginal sex acts with respective client type with robust variance estimation

\section{Multivariate Results}

\section{Non-regular clients}

In Tijuana, hormonal contraceptive use, higher numbers of regular clients, and injecting drugs around the time of sex (Risk rate ratio [RRR] = 1.64; 95\% confidence interval [CI] 1.29-2.09) were associated with more unprotected sex acts with non-regular clients (see Table 4), while higher positive outcome expectancy for condom use (RRR $=0.90$ per unit increase; 95\% CI 0.84-0.97) and always having free access to condoms $(\mathrm{RRR}=0.64 ; 95 \%$ CI $0.43-0.97$ ) were protective.

Risk-environment variables independently associated with a higher frequency of unprotected sex in Cd. Juarez included living in inadequate housing/homelessness (RRR $=1.38$; 95\% CI 1.15-1.66) and typically injecting drugs with more people (RRR = 1.02 per person increase; 95\% CI 1.00-1.03). Earning more for unprotected sex with clients was independently associated $(\mathrm{RRR}=0.85$; 95\% CI 0.74 0.98 ) with a decreased rate of unprotected sex among nonregular clients.

In both cities, higher self-efficacy regarding condom use was independently associated with a lower frequency of unprotected sex with non-regular clients.

\section{Regular clients}

In Tijuana, factors independently associated with a higher frequency of unprotected sex between FSW-IDUs and their regular clients included always using hormonal contraceptives (RRR $=1.10$; 95\% CI 1.01-1.19), typically injecting with more people $(\mathrm{RRR}=1.01$; $95 \%$ CI 1.00 1.01), and injecting with clients before or during sex (RRR = 1.43; 95\% CI 1.16-1.77). Unexpectedly, women living in unstable housing (RRR $=0.88$; 95\% CI 0.80-0.97) had less unprotected sex with regular clients than those in stable housing.

In Cd. Juarez, higher numbers of non-regular clients and earning $<3500$ pesos per month were associated with a higher frequency of unprotected sex with regular clients, whereas higher self-efficacy regarding condom use (RRR = 0.89 per unit increase; 95\%CI 0.81-0.98) was independently associated with lower frequency of unprotected sex with regular clients.

In both Cd. Juarez and Tijuana, higher positive outcome expectancy for condom use and earning more for unprotected sex were independently associated with a lower frequency of unprotected sex with regular clients. 
Table 4

Results of multivariate negative binomial regression of unprotected vaginal sex acts by client type among FSW-IDU in Ciudad Juarez

\begin{tabular}{|c|c|c|c|c|}
\hline \multirow[b]{2}{*}{ Variable } & \multicolumn{2}{|c|}{$\begin{array}{c}\text { Model 1 } \\
\text { \# of unprotected } \\
\text { sex acts with } \\
\text { non-regular clients } \\
(n=277)\end{array}$} & \multicolumn{2}{|c|}{$\begin{array}{c}\text { Model } 2 \\
\text { \# of unprotected } \\
\text { sex acts with } \\
\text { regular clients } \\
(n=248)\end{array}$} \\
\hline & RRR & $95 \% \mathrm{CI}$ & RRR & $95 \%$ CI \\
\hline \multicolumn{5}{|l|}{ Individual factors } \\
\hline \multicolumn{5}{|l|}{ Hormonal contraceptive use (always vs. less than always) } \\
\hline \multicolumn{5}{|l|}{ \# of clients (by client type) } \\
\hline Non-regular & & & 1.003 & $1.001-1.004$ \\
\hline \multicolumn{5}{|l|}{ Regular } \\
\hline \multicolumn{5}{|l|}{ Risk Environment (micro-level) factors } \\
\hline \multicolumn{5}{|l|}{ Physical Risk Environment } \\
\hline \multicolumn{5}{|l|}{ Housing categories (ref $=$ stable) } \\
\hline Unstable & 1.01 & $0.87-1.17$ & & \\
\hline Inadequate/homeless & 1.38 & $1.15-1.66$ & & \\
\hline \multicolumn{5}{|l|}{ Social Risk Environment } \\
\hline Number of people typically inject with & 1.02 & $1.00-1.03$ & & \\
\hline \multicolumn{5}{|l|}{ Inject with clients around time of sex (Any vs. Never) } \\
\hline Condom use self-efficacy (mean, CI, range = 1-4) & 0.88 & $0.80-0.96$ & 0.89 & $0.81-0.98$ \\
\hline Positive outcome expectancy for condom use (mean, CI, range $=1-4$ ) & & & 0.91 & $0.84-0.99$ \\
\hline \multicolumn{5}{|l|}{ Economic Risk Environment } \\
\hline Income (<3500 pesos/month) & & & 1.21 & $1.02-1.44$ \\
\hline Reported earning more for unprotected sex & 0.85 & $0.74-0.98$ & 0.77 & $0.65-0.91$ \\
\hline \multicolumn{5}{|l|}{ Policy Risk Environment } \\
\hline Free access to condoms (always vs. less than always) & & & & \\
\hline
\end{tabular}

Results of multivariate negative binomial regression of unprotected vaginal sex acts by client type among FSW-IDU in Tijuana

\begin{tabular}{|c|c|c|c|c|}
\hline \multirow[b]{2}{*}{ Variable } & \multicolumn{2}{|c|}{$\begin{array}{c}\text { Model } 3 \\
\text { \# of unprotected sex acts with } \\
\text { non-regular clients } \\
(n=218)\end{array}$} & \multicolumn{2}{|c|}{$\begin{array}{c}\text { Model } 4 \\
\text { \# of unprotected sex acts with } \\
\text { regular clients } \\
(n=230)\end{array}$} \\
\hline & RRR & $95 \%$ CI & RRR & $95 \%$ CI \\
\hline \multicolumn{5}{|l|}{ Individual factors } \\
\hline Hormonal contraceptive use (always vs. less than always) & 1.10 & $0.99-1.23$ & 1.10 & $1.01-1.19$ \\
\hline \multicolumn{5}{|l|}{ \# of clients (by client type) } \\
\hline \multicolumn{5}{|l|}{ Non-regular } \\
\hline Regular & 1.003 & $0.99-1.01$ & & \\
\hline \multicolumn{5}{|l|}{ Risk Environment (micro-level) factors } \\
\hline \multicolumn{5}{|l|}{ Physical Risk Environment } \\
\hline \multicolumn{5}{|l|}{ Housing categories (ref = stable) } \\
\hline Unstable & & & 0.88 & $0.80-0.97$ \\
\hline Inadequate/homeless & & & 0.88 & $0.75-1.02$ \\
\hline \multicolumn{5}{|l|}{ Social Risk Environment } \\
\hline Number of people typically inject with & & & 1.01 & $1.00-1.01$ \\
\hline Inject with clients around time of sex (Any vs. Never) & 1.64 & $1.29-2.09$ & 1.43 & $1.16-1.77$ \\
\hline Condom use self-efficacy (mean, CI, range $=1-4$ ) & 0.84 & $0.77-0.91$ & & \\
\hline
\end{tabular}




\begin{tabular}{|c|c|c|c|c|}
\hline \multirow[b]{2}{*}{ Variable } & \multicolumn{2}{|c|}{$\begin{array}{c}\text { Model } 3 \\
\text { \# of unprotected sex acts with } \\
\text { non-regular clients } \\
(n=218)\end{array}$} & \multicolumn{2}{|c|}{$\begin{array}{c}\text { Model } 4 \\
\text { \# of unprotected sex acts with } \\
\text { regular clients } \\
(n=230)\end{array}$} \\
\hline & $\mathbf{R R R}$ & $95 \%$ CI & $\mathbf{R R R}$ & $95 \%$ CI \\
\hline Positive outcome expectancy for condom use (mean, CI, range $=1-4$ ) & 0.90 & $0.84-0.97$ & 0.92 & $0.85-0.99$ \\
\hline \multicolumn{5}{|l|}{ Economic Risk Environment } \\
\hline \multicolumn{5}{|l|}{ Income (<3500 pesos/month) } \\
\hline Reported earning more for unprotected sex & & & 0.81 & $0.72-0.92$ \\
\hline \multicolumn{5}{|l|}{ Policy Risk Environment } \\
\hline Free access to condoms (always vs. less than always) & 0.64 & $0.43-0.97$ & & \\
\hline
\end{tabular}

Model 3 controlled for hormonal contraceptive use and the number of regular clients that were significant in multivariate analysis at the individual block level but were insignificant after adding risk environment block variables in hierarchical modeling.

\section{Discussion}

In this study of FSW-IDUs in two Mexican-United States border cities, the majority of women reported frequently having unprotected sex with both non-regular and regular clients in the past month. Independent of client type, study site, or individual factors, unprotected sex among FSWIDUs was largely associated with aspects of the physical, social, economic, and policy risk environment. These findings are consistent with existing results where riskenvironment correlates were more closely associated with HIV infection than individual-level characteristics (Strathdee et al., 2011).

Housing stability was the only physical risk-environment factor independently associated with unprotected sex. In $\mathrm{Cd}$. Juarez, being homeless or living in inadequate housing was independently associated with more frequent unprotected sex with non-regular clients. Similar findings were seen in Miami, where homeless FSWs were more likely to encounter clients that refused to use condoms than housed FSWs (Surratt \& Inciardi, 2004). However, living in unstable housing (i.e. a relative's or friend's house, workplace, or rented room) in Tijuana was associated with fewer unprotected sex acts with regular clients. Ideally measures of housing instability account for time living at that residence (Weir, Bard, O'Brien, Casciato, \& Stark, 2007), which we could not ascertain. As housing instability was high among FSW-IDUs and may impact factors such as condom storage and service location, longitudinal studies on the impact of housing stability on unprotected sex among FSW-IDUs are needed.

Among this sample of FSW-IDUs, multiple social riskenvironment factors related to injection practices were independently associated with unprotected sex. Injecting with more people was independently associated with an increased rate of unprotected sex with non-regular clients in Cd. Juarez and regular clients in Tijuana. This finding is disconcerting since injection with others increases the likelihood of shared equipment and intravenous transmission of HIV. Furthermore, injecting with clients around the time of sex was independently associated with increased rates of unprotected sex among both client types in Tijuana, which may compromise the negotiation of condom use (Shannon et al., 2009; Urada, Morisky, Pimentel-Simbulan, Silverman, \& Strathdee, 2012). Along the Northern Mexico border, male clients of FSWs similarly reported an association between use of drugs during sex and increased unprotected sex (Goldenberg et al., 2010). A previous report on Mujer Mas Segura data showed that injecting with clients around the time of sex is associated with a three-fold increase in HIV infection (Strathdee et al., 2011). While much exposure to HIV is attributable to sharing injection equipment, our results show an increased risk of HIV exposure through sexual transmission between clients and FSW-IDUs as a result of unprotected sex after injecting with clients, underscoring the need to simultaneously address risk from intravenous and sexual routes.

Other factors in the social environment, including selfefficacy regarding condom use and positive outcome expectancy for condom use, were independently associated with a lower frequency of unprotected sex acts regardless of client type. Given our findings, interventions able to improve self-efficacy and positive outcome expectancies for condom use among FSW-IDUs may be especially promising. A recent intervention in Tijuana and Cd. Juarez to increase condom use using a harm-reduction approach reduced HIV/STI incidence among FSW-IDUs by more than 50\% (Strathdee et al., 2013).

Economic factors independently associated with the frequency of unprotected sex acts included lower overall income and earning more money for unprotected sex. Regular clients in the border region have the lure of being financially lucrative and stable (Robertson et al., 2013), and women with less earning potential may experience more pressure from regular clients desiring unprotected sex. In addition, FSW-IDUs with limited resources for acquiring condoms may prioritize condom use with non-regular clients. Earning more money for unprotected sex was independently associated with fewer unprotected sex acts. Receiving more money for each transaction of unprotected sex may result in less financial need, leading to fewer clients and/or unprotected sex acts. However, Larios et al. (2009) found that in Cd. Juarez and Tijuana, earning more money for providing unprotected sex was associated with a higher frequency of unprotected sex acts among streetbased sex workers but not venue-based sex workers. More 
research on the micro-economics of protected versus unprotected sex and client load is warranted.

Regarding the policy risk environment, always having access to free condoms in Tijuana was independently associated with a decrease in the frequency of unprotected sex acts among non-regular clients in our study. Having access to free condoms has been associated with consistent condom use among FSWs (Cohen \& Farley, 2004; Kumar et al., 2006) and FSW-IDUs (Gaines et al., 2013), highlighting its importance as a critical enabler for HIV prevention among FSWs.

While many correlates of unprotected sex were similar across study sites, there were important site differences in the number of clients and the number and proportion of unprotected vaginal sex acts by client type. FSW-IDUs in $\mathrm{Cd}$. Juarez had a much higher volume of, and a higher median number of unprotected vaginal sex acts with, nonregular clients compared to FSW-IDUs in Tijuana. Whereas FSW-IDUs in Tijuana serviced more regular clients with whom they had more unprotected vaginal sex acts, overall, than in Cd. Juarez. Efforts to reduce the number of unprotected vaginal sex acts must recognize local context and differences in site, client type, and risk environment.

\section{Limitations}

Our study has important limitations that could impact our findings. Given that recent unprotected sex and injection drug use were inclusion criteria, our findings may be biased with regards to FSWs with a high-risk profile and the ability to generalize to broader groups of FSWs is reduced. At the same time, knowing the risk factors for unprotected sex in a group at high risk for HIV is important for tailoring interventions in this subpopulation. Self-reported sexual behavior may have resulted in recall or social desirability bias; participants were asked to recall many behaviors, including the number of vaginal sex acts by client type and the number of vaginal sex acts that were protected. We used trained outreach workers with experience working with both IDUs and sex workers to guide interview questions and reduce discomfort with the interviewer to minimize these biases.

\section{Conclusion}

While correlates of unprotected sex among FSW-IDUs differed between Tijuana and Cd. Juarez and by client type, physical, social, and economic aspects of the risk environment were most closely associated with frequency of unprotected sex among FSW-IDUs compared with individual aspects. Accordingly, altering FSW-IDUs risk environment is likely to have a greater impact on the number of unprotected sex acts than a focus on individual behaviors. Along the Northern Mexico border, such a holistic approach should include policies that ensure access to free condoms and address poverty among FSW-IDUs, programs that address housing stability for at-risk women, and interventions that acknowledge the social context of FSW-client interactions.

\section{References}

Alary, M., \& Lowndes, C. M. (2004). The central role of clients of female sex workers in the dynamics of heterosexual HIV transmission in sub-Saharan Africa. AIDS, 18(6), 945-947.

Buchacz, K., van der Straten, A., Saul, J., Shiboski, S. C., Gomez, C. A., \& Padian, N. (2001). Sociodemographic, behavioral, and clinical correlates of inconsistent condom use in HIV-serodiscordant heterosexual couples. Journal of Acquired Immune Deficiency Syndromes, 28(3), 289-297.

Campsmith, M. L., Nakashima, A. K., \& Jones, J. L. (2000). Association between crack cocaine use and high-risk sexual behaviors after HIV diagnosis. Journal of Acquired Immune Deficiency Syndromes, 25(2), 192-198.

Cohen, D. A., \& Farley, T. A. (2004). Social marketing of condoms is great, but we need more free condoms. Lancet, 364(9428), 13-14. doi:10.1016/S01406736(04)16611-7

Gaines, T. L., Rudolph, A. E., Brouwer, K. C., Strathdee, S. A., Lozada, R., Martinez, G., . . Rusch, M. L. (2013). The longitudinal association of venue stability with consistent condom use among female sex workers in two Mexico-USA border cities. International Journal of STD \& AIDS, 24(7), 523-529. doi:10.1177/ 0956462412473890

Goldenberg, S. M., Gallardo Cruz, M., Strathdee, S. A., Nguyen, L., Semple, S. J., \& Patterson, T. L. (2010). Correlates of unprotected sex with female sex workers among male clients in Tijuana, Mexico. Sexually Transmitted Diseases, 37(5), 319-324. doi:10.1097/OLQ.0b013e3181c5334f

Hong, Y., \& Li, X. (2008). Behavioral studies of female sex workers in China: A literature review and recommendation for future research. AIDS and Behavior, 12(4), 623-636. doi:10.1007/s10461-0079287-7

Jamner, S., Wolitski, R. J., Corby, N. H., \& Fishbein, M. (1998). Using the theory of planned behavior to predict intention to use condoms among female sex workers. Psychology \& Health, 13(2), 187-205. doi:10.1080/08870449808406746

Kumar, G. A., Dandona, R., Gutierrez, J. P., McPherson, S., Bertozzi, S. M., \& Dandona, L. (2006). Access to condoms for female sex workers in Andhra Pradesh. The National Medical Journal of India, 19(6), 306312.

Larios, S. E., Lozada, R., Strathdee, S. A., Semple, S. J., Roesch, S., Staines, H., . . Patterson, T. L. (2009). An exploration of contextual factors that influence HIV risk in female sex workers in Mexico: The Social Ecological Model applied to HIV risk behaviors. AIDS Care, 21(10), 1335-1342. doi:10.1080/ 09540120902803190

Lau, J. T., Zhang, J., Zhang, L., Wang, N., Cheng, F., Zhang, Y., . . . Lan, Y. (2007). Comparing prevalence of condom use among 15,379 female sex workers injecting or not injecting drugs in China. Sexually Transmitted Diseases, 34(11), 908-916. doi:10.1097/OLQ.0b013e3180e904b4 
Morris, M., Pramualratana, A., Podhisita, C., \& Wawer, M. J. (1995). The relational determinants of condom use with commercial sex partners in Thailand. AIDS, 9(5), 507-515.

Munoz, F. A., Pollini, R. A., Zuniga, M. L., Strathdee, S. A., Lozada, R., Martinez, G. A., . . . Patterson, T. L. (2010). Condom access: Associations with consistent condom use among female sex workers in two northern border cities of Mexico. AIDS Education and Prevention, 22(5), 455-465. doi:10.1521/ aeap.2010.22.5.455

Patterson, T. L., Mausbach, B., Lozada, R., Staines-Orozco, H., Semple, S. J., Fraga-Vallejo, M., . . . Strathdee, S. A. (2008). Efficacy of a brief behavioral intervention to promote condom use among female sex workers in Tijuana and Ciudad Juarez, Mexico. American Journal of Public Health, 98(11), 2051-2057. doi:10.2105/AJPH.2007.130096

Pettifor, A., Turner, A. N., Swezey, T., Khan, M., Raharinivo, M. S., Randrianasolo, B., . . . Behets, F. (2010). Perceived control over condom use among sex workers in Madagascar: A cohort study. BMC Women's Health, 10, 4. doi:10.1186/1472-6874-10-4

Pickering, H., Okongo, M., Nnalusiba, B., Bwanika, K., \& Whitworth, J. (1997). Sexual networks in Uganda: Casual and commercial sex in a trading town. AIDS Care, 9(2), 199-207. doi:10.1080/ 09540129750125217

Ramos, R., Ferreira-Pinto, J. B., Brouwer, K. C., Ramos, M. E., Lozada, R. M., Firestone-Cruz, M., \& Strathdee, S. A. (2009). A tale of two cities: Social and environmental influences shaping risk factors and protective behaviors in two Mexico-US border cities. Health \& Place, 15(4), 999-1005. doi:10.1016/j. healthplace.2009.04.004

Rhodes, T., Singer, M., Bourgois, P., Friedman, S. R., \& Strathdee, S. A. (2005). The social structural production of HIV risk among injecting drug users. Social Science \& Medicine, 61(5), 1026-1044. doi:10.1016/j.socscimed.2004.12.024

Rhodes, T., Stimson, G. V., Crofts, N., Ball, A., Dehne, K., \& Khodakevich, L. (1999). Drug injecting, rapid HIV spread, and the 'risk environment': Implications for assessment and response. AIDS, 13(Suppl A), S259S269.

Robertson, A. M., Syvertsen, J. L., Rangel, M. G., Staines, H. S., Morris, M., Patterson, T. L., . . Strathdee, S. A. (2013). Concurrent sexual partnerships among female sex workers and their non-commercial male partners in Tijuana and Ciudad Juarez, Mexico. Sexually Transmitted Infections, 89(4), 330-332. doi:10.1136/sextrans-2012-050693

Semple, S. J., Strathdee, S. A., Gallardo Cruz, M., Robertson, A., Goldenberg, S., \& Patterson, T. L. (2010). Psychosexual and social-cognitive correlates of sexual risk behavior among male clients of female sex workers in Tijuana, Mexico. AIDS Care, 22(12), 1473-1480. doi:10.1080/09540121003758648

Shannon, K., Strathdee, S. A., Shoveller, J., Rusch, M., Kerr, T., \& Tyndall, M. W. (2009). Structural and environmental barriers to condom use negotiation with clients among female sex workers: Implications for
HIV-prevention strategies and policy. American Journal of Public Health, 99(4), 659-665. doi:10.2105/AJPH.2007.129858

Strathdee, S. A., Abramovitz, D., Lozada, R., Martinez, G., Rangel, M. G., Vera, A., . . . Patterson, T. L. (2013). Reductions in HIV/STI incidence and sharing of injection equipment among female sex workers who inject drugs: Results from a randomized controlled trial. PLOS ONE, 8(6), e65812. doi:10.1371/ journal.pone.0065812

Strathdee, S. A., Lozada, R., Martinez, G., Vera, A., Rusch, M., Nguyen, L., . . . Patterson, T. L. (2011). Social and structural factors associated with HIV infection among female sex workers who inject drugs in the MexicoUS border region. PLOS ONE, 6(4), e19048. doi:10.1371/journal.pone.0019048

Strathdee, S. A., Philbin, M. M., Semple, S. J., Pu, M., Orozovich, P., Martinez, G., . . . Patterson, T. L. (2008). Correlates of injection drug use among female sex workers in two Mexico-U.S. border cities. Drug and Alcohol Dependence, 92(1-3), 132-140. doi:10.1016/j.drugalcdep.2007.07.001

Surratt, H. L., \& Inciardi, J. A. (2004). HIV risk, seropositivity and predictors of infection among homeless and non-homeless women sex workers in Miami, Florida, USA. AIDS Care, 16(5), 594-604. doi:10.1080/09540120410001716397

Tran, T. T., Le, C. L., \& Nguyen, T. L. (2008). Factors associated with inconsistent condom use among female sex workers in Nha Trang, Vietnam. AsiaPacific Journal of Public Health / Asia-Pacific Academic Consortium for Public Health, 20(4), 370378. doi:10.1177/1010539508322485

Urada, L. A., Morisky, D. E., Pimentel-Simbulan, N., Silverman, J. G., \& Strathdee, S. A. (2012). Condom negotiations among female sex workers in the Philippines: Environmental influences. PLOS ONE, 7(3), e33282. doi:10.1371/journal.pone.0033282

Vera, A., Abramovitz, D., Lozada, R., Martinez, G., Rangel, M. G., Staines, H., . . . Strathdee, S. A. (2012). Mujer Mas Segura (Safer Women): A combination prevention intervention to reduce sexual and injection risks among female sex workers who inject drugs. BMC Public Health, 12, 653. doi:10.1186/1471-2458-12-653

Victora, C. G., Huttly, S. R., Fuchs, S. C., \& Olinto, M. T. (1997). The role of conceptual frameworks in epidemiological analysis: A hierarchical approach. International Journal of Epidemiology, 26(1), 224227.

Wang, C., Hawes, S. E., Gaye, A., Sow, P. S., Ndoye, I., Manhart, L. E., . . . Kiviat, N. B. (2007). HIV prevalence, previous HIV testing, and condom use with clients and regular partners among Senegalese commercial sex workers. Sexually Transmitted Infections, 83(7), 534-540. doi:10.1136/sti.2007. 027151

Weir, B. W., Bard, R. S., O'Brien, K., Casciato, C. J., \& Stark, M. J. (2007). Uncovering patterns of HIV risk through multiple housing measures. AIDS and Behavior, 11(6 Suppl), 31-44. doi:10.1007/s10461007-9284-X 
170 Ryan P. Lindsay et al.

Wilson, T. E., Massad, L. S., Riester, K. A., Barkan, S., Richardson, J., Young, M., . . Greenblatt, R. (1999).

Sexual, contraceptive, and drug use behaviors of women with HIV and those at high risk for infection: Results from the Women's Interagency HIV Study. AIDS, 13(5), 591-598. 